\title{
Using Skype in a Primary Class: A Case Study
}

\author{
Aida Cuestas Verjano, Universitat Autònoma de Barcelona, \\ Barcelona, Spain
}

(Article received 13 January 2013; final version received 16 April 2013)

\begin{abstract}
The important role of new technologies to communicate in the globalized world we live in cannot be denied. Teachers must take this fact into account and help their students construct their knowledge through computer-mediated learning in order to better understand how these tools function. In the context of Teaching English as a Foreign Language (TEFL), Computer-Mediated Communication (CMC) has become a powerful tool for learning, as these resources give meaning and realworld relevance to language teaching practices and activities. This smallscale study describes the implementation of an interactional activity, rooted in sociocultural theory, which used Skype as teaching tool. The data stemming from the investigation provides evidence to support the argument that digital resources for foreign language learning hold great potential as mediating tools for increased motivation and enhanced peer interaction.
\end{abstract}

\section{Introduction}

This article describes the implementation of a small-scale intervention in a Catalan primary school that utilized technology as a means of promoting authentic language use with young learners. The text outlines the data compilation and reports some findings resulting from the project. The main objective of the study carried out during the teaching experience was to observe and compare specific instances of classroom interaction, and to demonstrate how the use of a synchronous digital tool can affect the interactional activity of students.

In the last three decades, foreign language pedagogy has increasingly been characterized by a communicative focus, leaving behind cognitive and individual-centered understandings of learning; this research departs from the basic premises of this approach, in which language, language learning and language teaching are seen as essentially functional features of everyday life. This implies that language learning (and subsequent target language use) must be contextualized within the needs of the globalized and increasingly interconnected society we live in. 
Living in a globalized and network-based context in which new technologies are used in every single aspect of our lives, through a great variety of devices (from mobiles, to tablets, PDAs and computers), language teachers (and educators in general) should teach their students how to develop and act in an autonomous way in this technology-based world. More importantly to this study, there is a growing need for future professionals to be able to communicate in English through these $21^{\text {st }}$ century devices, so it stands to reason that they can start acquiring these integrated skills while at school (Dooly, 2010). Within the same context, the use of computers in English as a Foreign Language classes can enhance the real necessity for students to communicate in English, thereby motivating them, bringing them to higher levels of participation, and providing the opportunity for greater amount and quality of language use.

Bearing these two factors (communication and technology) in mind, language teachers should start rethinking how to revamp their teaching approaches in order to ensure all children's inclusion in this globalized, interconnected world. If learning to effectively communicate in the foreign language is the primary and perhaps the most relevant goal in language education and Information and Communication Technology (herein ICT) is so important in the current culture, joining both features to improve learner's learning processes would seem to be more than an appropriate response to the need to innovate in language teaching.

In this light, this article describes a small-scale teaching experiment in which the target language (English) is used by the students to carry out a specific function: to talk about and suggest important sites in Catalonia for tourists who want to come for a visit to their region. This paper is part of a more extended action research project carried out in a primary classroom, in which a contextual problem was identified (lack of students' communication skills), a plan was proposed (an ICT activity using the free Internet video calling application Skype) and then the teaching plan was implemented. The results of this trial class were then compared to another learning situation that did not include the use of Internet as communication tool and conclusions about its efficacy were drawn.

The purpose of this investigation was to add to current efforts being made in the field of Computer-Assisted Language Learning by examining if the use of 21st century tools, such as Skype can bring significant benefits to the process of language learning and in what ways. Concretely, this article describes a language learning experience as an immersion-type 
exposure' to language, facilitated by Skype. The learning situation involved interaction with a native speaker of English who did not speak or understand Spanish or Catalan, which presented the need to the students to interact in the target language as a means to communicate for an authentic purpose. Underlying this approach is the acknowledgment that setting up opportunities for real interaction that is not teacher-centered and that the principal aim of teaching plans may also include peer-to-peer collaborative work facilitated by new technologies.

\section{Sociocultural Approaches to Language Teaching}

Sociocultural approaches are deeply rooted in Vygotskyan theories and over time have become characterized by their changing status within the educational community (Bruner, 1985). Still, one aspect that has been perpetually present is the initial concept of culturally mediated higher-order mental functioning. In the early $20^{\text {th }}$ century, Vygotsky, in contrast to Piagetian theories, hypothesized that, "development does not proceed toward socialization, but toward the conversion of social relations into mental functions" (Vygotsky, 1981, p. 165). He argued that tool and sign mediation underlie the development of higher order cognitive functions (Vygotsky, 1978; 1981). More specifically, his theory contends that human mental functioning is fundamentally a "mediated" process, which is organized by cultural artifacts, activities, and concepts (Ratner, 2002). Within this framework, humans actively engage with existing cultural artifacts in their social surroundings to regulate their biological and behavioral activity and eventually transform them to create new environments (Lantolf \& Thorne, 2006:197). Following on Vygotsky, the Sociocultural Theory of mind (henceforth SCT) also states that human cognitive activity develops through interaction within real social environments such as the school and family (ibid.: 198).

Historically, drawing on Vygotsky's theory and particularly the concept of Zone of Proximal Development (ZPD), it has been thought that the learning process has to be constructed by an expert (traditionally an adult) that helps a novice (the student). Nevertheless, as some experts have stated (Tudge, 1990; Wells, 1999; Brooks \& Swain, 2001; Kowal, \& Swain, 1997), peer-to-peer interaction can also become a good way to accomplish this tandem. According to Swain, Brooks \& Tocalli-Beller (2002, p. 172-173) "peers working within the frame of their respective ZPD can support learning through, for example, questioning, proposing possible solutions, disagreeing, repeating, and managing activities and 
behaviors (social and cognitive)". Furthermore, in peer-to-peer interaction, already learned language becomes a mediator to learning new language, which implies that language is not only a means, but also the outcome and the process.

In the frame of SCT, Dooly affirms that

knowledge is constructed, and transformed by students. The learning process must be understood as the activity in which a learner activates already existent cognitive structures or by constructing new cognitive structures that accommodate new input. Learners do not passively receive knowledge from the teacher; rather, teaching becomes a transaction between all the stakeholders in the learning process. (Dooly, 2008: 22)

In other words, there is a constant interaction between the person and the environment, the individual and the socio-material world, which is known as mediation. In this sense, in the learning activity presented in this document, both the use of language and the digital resources for communicating serve as mediating tools to develop the language acquisition process and to promote further interaction among the learners.

Apart from the importance of language in learning theories such as SCT, the teaching experience was also based in sound language teaching principles that have emerged in the past few decades, in particular, the Communicative Language Teaching Approach (CLT). According to Richards (2006), CLT can be defined as a set of principles about the goals, the methods, the activities and the role of teachers for language learning and teaching. It is not enough for foreign language learners to 'know about' the language - communication also involves pragmatic, prosodic and cultural features that are inherent to the language. Every culture has a way of speaking, with different speech rules and diverse body language behaviors and turn-taking routines. Thus, learners must know these social and cultural characteristics (apart from knowing how to use the grammatical aspects of the specific language) in order to be able to interact and understand meaning in the target language appropriately. This is a basic premise underlying the so-called Communicative Approach for Language Teaching, which emerged in the 1970's.

Consequently, interest in competences was raised amongst researchers in language acquisition. Communicative competence was defined by Breen and Candlin as the ability to "share and negotiate meanings and conventions" (1980, p. 92). Savignon (1983, p. 307) defined it as "a process whereby a participant in a speech event uses various sources of information - prior experience, the context, another participant - to achieve understanding". In CLT, foreign language teachers (who act both as co-learners and learning 
conductors) should create an educational environment in which students are exposed to the social constraints of today's world and in which they can interact to arrange a similarly negotiated meaning about the message they are sharing. Real and interactional activities which prioritize functions over form become relevant, and they must give students the opportunity to experiment with language in different contexts of use and which allow them to pay attention to both fluency and accuracy (Richards, 2006).

One approach to research and practice that reinforces the importance of using the language as both the means and object to be learnt is the use of new technologies; as will be outlined in more detail further on, digital tools can become mediating artifacts in the language classroom that promote the use of the language as a means to learning the language. This might be why socioconstructivist approaches have played such an important role in research into technology-enhanced language learning, especially in the use of Computer-Mediated Communication for teaching and learning (Dooly, 2010). Nevertheless, nowadays it seems that there is not a single method to follow to achieve these goals. CLT and its derived teaching approaches such as task-based learning are still predominant, some other approaches have disappeared, and a great amount of new methods are arising, many of which are being mixed with the preexistent ones. Yet, there appears to be a general agreement that the language learning process needs to be considered in relation to its context. It is believed that students need to be exposed to the target language and use it in situational contexts. This article describes the outcomes of an activity that sought to operationalize these premises in pedagogical practice. Following the lines of CLT, the different activities were specifically planned to take into account the students' context and their exposure to authentic language and provide a real purpose for the target language use.

Moreover, oral communication does not only consist of only speaking but also brings into play listening competences and the ability to interpret the meaning of the conversation through the social and cultural context (Rivers, 1993). Thus, it can be hypothesized that this type of CMC interaction is a collaborative activity (student-student interaction, teacherstudent-interaction and NS-student interaction) whereby students are motivated to use actual communication in situations of natural conversation (Rivers, 1993). 


\section{Technology and Language Teaching}

As it has been previously stated, technology has become an inextricable part of everyday life, bringing about the need for the development of new literacies, skills and competences (Kress \& van Leeuwen, 2001; Kress, 2003; Thorne, Black \& Sykes, 2009). This fact has brought new challenges and new goals to reach for educational enterprise; arguably online communication or interaction almost seems commonsensical as a way to create mediation processes that lead to learning opportunities for learners in the $21^{\text {st }}$ century.

Computer-Mediated Communication (henceforth CMC) or Network-based Language Learning (NBLL) are the terms used to refer to the communication established when computers are used to engage students in real interactions with other speakers of the target language. Their focus is to emphasize interaction among students, leaving behind individualism and promote collaboration and group participation (Dooly, 2008). Early research on network-based language learning focused on the linguistic and affective features of computer-assisted language learning, while contemporary research tends to be focalized on long-distance collaboration (Kern, Ware, \& Warschauer, 2004). Society (and learners) have evolved in tune with the development of new technologies, which means that asynchronous tools are now being used along with new synchronous resources, all of which have become a significant focus of recent research.

Nonetheless, little research has been carried out on the use of technology tools (specially of videoconferencing) for foreign language learning at Primary schools in Catalonia, however, some examples can be taken from the US context, where CMC has its origins and is increasingly being researched. According to Kern, Ware and Warschauer (2004), current studies on this field are based on three main lines of research: linguistic interaction, intercultural learning and literacy and identity. The first category places special emphasis on negotiation of meaning, and research in this area has largely focused on counting or categorizing individual students' comments or investigating the relationships among language outcomes, online tools used and its uses. Some important studies, using chats as the main technological devices, are the ones from Blake (2000) or Smith (2003). The second line of research not only has as main focus of study the development of students' language but also the enrichment in their intercultural competence. Cummins and Sayers (1995), Kern (2000), O'Dowd (2006), and Dooly and Sadler (2013) among others have brought up relevant data on this topic. Important investigations on the latter line of research, carried out by 
Warschauer (1999; 2000) and Lam (2000), looked at how identity developed through online tools had an effect on language development.

What must be clear among all the current trends is that the use of Internet technologies to enhance dialogue among individuals in an educational context "proposes a compelling shift in L2 education, one that moves learners away from simulated classroom-based context and toward actual interaction with expert speakers of the language they are studying" (Thorne, 2008: 426). It seems logical then to perceive the use of Computer -Mediated Communication as an advantageous methodology for foreign language teaching.

Communicative practices are not determined by the medium but they are negotiated through "cultures of use" (Thorne, 2003), which are the "norms and attributions that evolve out of everyday use of a medium" (Kern, Ware, \& Warschauer, 2004). Technologies, as cultural artifacts, have different meanings, uses and utilities for different communities (Thorne, 2008). For example, in a telecollaboration research carried out by the same author, it could be observed how the choice of e-mail as a tool communication was not as appropriate for student's interactions as instant messaging, and these personal exchanges improved when users switched to instant messaging. According to Thorne

cultural, individual and collective historical factors influence the way students perceive Internet communication tools and their (mis)uses provide insight into relationships between language use, mediational means, levels of engagement, and the potential for authenticity in the communicative process, all of which are implicated in the activity of language development. (Thorne, 2003: 58)

Adding to this stream of thought, Dooly (2010) states that the main teaching approach when using digital resources is learner-centered, not technology or teacher-centered: students have to be able to use these resources effectively to collaborate among themselves and to coconstruct knowledge to learn, but it is neither the technology that directs this process nor the teacher. Technology in this case acts as a mediating artifact.

With all of these notions in mind, a videoconferencing tool (Skype) was chosen to be used in this research because there was a need to put children in touch with a native person to carry out a more authentic speaking task. Skype was chosen over other videoconferencing tools mainly because it is a free online application that was a practical solution for the teacher at that moment. Additionally, in relation to Culture-of-use, also the pupils' opinions were taken into account for the digital tool choice. Skype was familiar to them as many of them had 
used it to communicate with classmates who were not at school. This implied that they would probably be more comfortable when using it in class. Moreover, the application was already installed in the school computer.

\section{Research Methodology}

The students who were the focus of this qualitative research seemed to show difficulties communicating orally in the L2 they were learning. Generally oral language among students was not highly promoted in the school syllabus and consequently, the speaking skills of the students in the group were quite low (taking as a premise the core contents of the Curriculum in Catalonia). For this reason, the researcher, who was also the language teacher in this class, decided to implement an activity aimed to improve the speaking competences of this particular group. To promote this process and solve the learning problem encountered, the teacher-researcher chose the Action Research approach to collect and analyze the data, subsequently the observations and reflections taken through this method were coded and interpreted within the paradigm of Grounded Theory (Glaser \& Strauss, 1967). The findings were then used to discern whether this type of activity is indeed valuable as a means of improving oral competences in the target language.

The main reason to take on Action Research (henceforth AR) as the investigation methodology was because it is a systematic and reflective methodology of study that implies observing a context and to take actions to have an effect on it. This means that it is not just a method to collect and analyze data, but a holistic approach to problem solving (Riel, 2011; O'Brien, 2001), perfectly suitable for the context described. It could be said that it is a dual method of investigation in which the main objectives are to seek problematic features in specific contexts and to plan and carry out diverse actions to improve the situation among these contexts (Riel, 2011; O'Brien, 2001). This means that AR is a situational, contextual, collaborative, participatory and self-evaluative method (Op. Cit.). As such, the researcher is primarily interested in gaining knowledge about a specific situation and not to generalize or extrapolate results precisely because they are mainly based on the context in which they emerged (Cohen \& Manion, 1980; Dick \& Swepson, 2012). In other words, generalizability of findings is not a main aim of AR endeavors/implementations but instead, the primary concern is to present the findings for the researchers and their collaborators in relation to their contextual relevancies. 
Generally, the way AR is carried out is the following. The researcher takes into consideration a specific problem or question she would like to explore in more depth. The researcher then plans relevant actions that might resolve the problem or provide an answer to the posed question. After implementing the planned actions in the educative community, researchers (often researcher-teacher) investigate the results and then, after a thorough analysis, propose new actions.

In the case of this research, a similar process was applied. Firstly, the teacherresearcher observed a problem related to her pupils (they did not commonly use conversational English in the FL lesson). Then, she as a researcher planned an action to implement and overcome this situation encountered: she set out the use of ICT as a method which could enhance target communication in the classroom and proposed two activities to analyze in order to be able to compare results and then discern implications for effective pedagogical language learning practice in primary education. After the teacher-researcher had carried out the process of analysis and conclusions, some proposals were made for further research and improvements.

\section{The context and the two activities}

The activities were implemented with a 11-12 year-old group of 23 students from a Primary State school in Catalonia. These pupils were used to working with text-books, and were not at all familiar with following a communicative approach perspective. Generally all the contents were organized around specific topics and chunks of language that had to be learnt. The children in the study were working on a topic-based unit in which they were expected to learn to talk about their city (describing cities). To do so, they learnt general vocabulary needed to discuss the topic of 'city' and studied the use of forms there is/are. Taking into account the lack of communicative tasks proposed by the book, the main aim of the designed activities was to turn these contents into more communicative ones and it was decided that the use a digital tool would facilitate this.

So, the designed task related to the current syllabus was to make a written proposal for tourists who would like to visit their town (e.g. things to do and see, places to eat, etc.). The teacher explained to the children that they had to imagine that they worked for a tourism office and they had to give some tips about what to do and where to go in the surroundings of 
their village. To do the activity, the students had to work in groups and complete a worksheet in which they had to propose some tourism activities and tips. This step lasted for one session of one hour (session 1). In the next session also of one hour (session 2), the teacher-researcher had already examined the students' proposals (the worksheets) and had prepared some oral questions to ask the students (about their proposals). In the next lesson (session 3), students received a Skype video call from Kate who was presented as a friend of the teacher and who worked in a tourism office in the U.S.A. The students were told that Kate was interested in gathering tourism information about Barcelona. She asked the children questions about the city (similar to the ones asked in session 2), trying to create the need for the children to really speak in English. The activities in session 2 were designed to contrast the results obtained from the digital-based activity in session 3 in order to analyze and compare the communication that occurred in both situations. To do so, similar questions were asked in both sessions.

\section{Methodology and process of data analysis}

For the data analysis, a constructivist approach through Grounded Theory (GT) was chosen because this research methodology allowed the investigator to direct, manage and construct an original data analysis in a systematic, yet flexible way. The method, originally conceived by Glaser and Strauss in 1967, consists in a reconstruction of experiences and meaning and eventually the construction of new theory. This new theory is "grounded" on the data itself (Charmaz, 2006), and does not rely on testing preconceived ideas. GT entails an extensive and exhaustive code-based qualitative analysis which helps the researcher to make sense of the complex processes taking place in the reality studied. As Charmaz (2006) points out, grounded theories emerge at the intersection of analysis of interactions among people, theoretical perspectives and research practices.

In accordance with the objectives of the study, the GT approach was operationalized as follows: First, two kinds of data were selected, which would allow a comparison of similar communicative events in two different mediation settings (digital-based and non-digital based). The first one was the oral session where the children were asked questions by the teacher (session 2), and the second one, the session with Skype (session 3). Both activities aimed to provide opportunities for the learners to engage with the comparable language use 
(e.g. related questions were asked about the same topics). The data for the analysis were compiled in these two sessions of one hour each.

The main procedure for collecting the data was video recording. After recording both sessions, the teacher-researcher transcribed all the compiled data. It should be noted that the transcription did not include phonetic aspects of the interaction as the intention was mainly to observe the English/Catalan language used and the kind of interventions done in line with the questions of this research.

Following the GT approach to data analysis, the teacher-researcher first watched the two hours of video recording and chose specific extracts that were relevant to the objectives of the study which could then analyzed in relation to the themes codified through GT (categories were derived concurrent to the first video observations). To do so, the teacherresearcher watched the recordings again to make a first rough list of possible indicators or characteristics according to the most notable features in order to consciously determine the codes surfacing from the data. Thus, during the transcribing process of the dialogues from the videos, the teacher-researcher was able to come up with a first set of codes, and then redefine them into categories. Moreover, the iteration and detailed analysis that stems from transcribing allowed her to reaffirm that the features observed had really emerged from the recorded data and it was not just a random or personal impression.

In the research project, both linguistic and non-linguistic indicators were observed from the data. These included categories such as the students' focus on topic, the vocabulary range used, their appropriateness of language use, their willingness or rejection to speak, their displayed motivation and engagement with the two tasks and even student opinions of the activities. However, this article outlines the most relevant characteristics observed from the data and which are related to the benefits of using ICT for oral English. They are related to the categories of 'peer-scaffolding' and 'engagement' in speaking activities which emerged from the GT preliminary analysis.

\section{Data analysis and discussion}

Peer-to-peer interaction

Comparing the two recordings from the two different sessions, it was observed that in both situations mostly the same children were participating. Nevertheless, the way those participators were intervening in the conversations was quite different. This differentiation of 
interventions was characterized principally by the way pupils interacted with each other (student-student interaction). In the case of the Skype session, in comparison to the other session, interaction did not always follow the usual pattern of classroom interaction of teacher question, student's reply, evaluation of the reply (Mehan, 1985), perhaps due to the greater student-to-student interaction and the relative absence of teacher assessment (Kern, 1995). The fact that there was a student (Mike) whose mother-tongue was English served as an additional tool to build this process of language learning by language use among peers, as he enabled more communicative situations adapted to the rest of the pupils' context and served as a 'bridge' between the adult speaker (Kate) and the rest of students in the Skype session, since he could understand everything and help his peers to communicate in the target language. This type of interaction was not observed in the teacher-fronted session (session 2).

In addition, as can be seen in Extract 1, peer-to-peer interaction for language learning mediation did not only occur with Mike's interventions, it also took place between other students. However, this mediation process only occurred in the Skype session, in contrast, in the normal class, students did not interact among themselves to construct language.

For example, in the next conversation, Mike apparently dictated what Jordi should answer to Kate's question.

Extract 1. Mike provides peer scaffolding

$\begin{array}{|ll|}\text { 427. } & \text { Kate What is la Sagrada Famlia? What is it? } \\ \text { 428. } & \text { Mike XXXX (He whispers something to Jordi) } \\ 429 . & \text { Teacher But Mike! } \\ 430 . & \text { Jordi A brilliant monument famous in Barcelona. } \\ 431 . & \text { Kate Ok, thank you. Ok, Sagrada Familia... What else can you suggest? } \\ 432 . & \text { Mike XX (He says something again to Jordi) } \\ 433 . & \text { Jordi The Parc Güell. } \\ 434 . & \text { Kate Ok, so that's a park? yes, a park? } \\ 435 . & \text { Jordi Yes. } \\ 436 . & \text { Kate Ok. What's special about this park? } \\ 437 . & \text { Jordi (To the teacher) Que té d'especial? } \\ 438 . & \text { Teacher Yes. }\end{array}$


Although it is not possible to distinguish Mike's exact words to Jordi, the context and the teacher's in situ observations suggest that he was advising Jordi on what to say, that is, he was facilitating language support to his classmate.

In the next example, Kate had asked about typical food from the region and Mike continued the conversation. Immediately, some other students contributed with their own suggestions. By opening the sequence with recognizable key words, Mike facilitated understanding of the question for his peers. He first contributes his own idea, which let the rest of students take the initiative and add their suggestions. The interactions stimulated students' interest in the interaction while contributing to peer learning (Kern, 1995).

Extract 2. Mike initiates sequence

261. Kate Aah! Ok, ok. Eeeh, then, what about something to eat? What places are there? Is there good food?

262. Mike Yes.

263. Kate Ok, can you tell me some ideas of what to eat?

264. Mike Paella.

265. Kate Paella, ok. What else?

266. Other students Escudella.

267. Xavi Marisco.

268. Kate What is that?

269. Mike Fish.

270. Teacher Seafood.

271. Mike Seafood.

272. Kate Seafood! Oh, nice. Do you like seafood?

273. Other students Noooo!

In the next extract, the peer-to-peer interaction did not only occur between Mike and their classmates, but also among the rest of the classmates.

Extract 3. Non-expert peer scaffolding

\begin{aligned} & 145. Kate Hello! You're very tall! \\ & 146. Àngel Hello! \\ & 147. Àngel My name is Àngel. \\ & 148. Kate Oh Àngel. \\ & 149. Xavi [Di algo] \\ & \hline\end{aligned}


150. Other students XXX

151. Teacher Sssh!

152. Àngel Uhhhh...

153. Xavi (In a low voice) Àngel. I life* in Santa Maria de Palautordera

154. Àngel I life* in Santa Maria de Palautordera.

155. Other students XXX

156. Xavi I... I am eleven years old.

157. Àngel I life eleven...

158. Xavi No! I life* no! Is! Is eleven years old.

159. Mike XXX

160. Erica Eh! Calleu!

161. Àngel Eleven...

162. Xavi Years...

163. Àngel Years...

164. Xavi old.

165. Àngel old.

166. Kate Ok! You're eleven years old, like your friend Xavi. The same, yes? Ok, nice to meet you Àngel.

In this excerpt, Ângel appeared to have difficulties introducing himself. Xavi, as the "more knowledgeable other", helped him to use the appropriate language to communicate; it is then, arguably, a clear case where corrective feedback contributed to students producing more appropriate target forms (Pica, 1994; Gass \& Varonis, 1994). Moreover, in this case, Kern, Ware and Warschauer's suggestion is reaffirmed: "CMC provides an ideal medium for students for interaction" (2004:244).

Several researches have shown how CMC interaction can facilitate the use of new lexical patterns (e.g. Pelletieri, 2000; St. John \& Cash, 1995) and something similar occurs in the excerpts shown above -the students did not integrate new lexicon in the Session 2 and they did not attempt to facilitate answers for the teacher-fronted question-answer sequences. It can be argued that the 'authentic' communicative event provided more opportunities for the pupils to construct knowledge together (Warschauer, 1997). 


\section{Student's need to speak}

To communicate (in any language) arises from an intrinsic need, which is provided by the context and not "because the teacher said so". In educational settings, there is little reason for students to engage in communication if there is no real purpose, apart from responding to the teacher. Network-based tools can provide possibilities for such authenticity and promote students' motivation and need for communication. As it will be shown later, throughout the observation of the two conversations this fact was reaffirmed. The data analysis revealed that there were differences in the ways that the students experienced the need to speak, according to the context of the activities. In fact, this seemed to be a major difference between session 2 and 3 (teacher-fronted interaction versus CMC interaction with a "real person"). For the pupils, it did not seem to feel like a normal class but an authentic context in which they really experienced the relevance of using the foreign language.

In the teacher-fronted class situation, the teacher repeatedly asked questions from a worksheet that the students had already spent time answering (and which had been handed in previously and revised by the teacher). As indicated in the following extract, students seemed to have difficulties understanding why the teacher was asking the same questions from the worksheet, if she had the information written down on the worksheets she had in her hand.

Extract 4. Teacher asks about answers in worksheets

18. Teacher Ok, family and couples, yes? So, those who thought about a family, what kind of things are there in here, around here to do? What kind of things did you think?

19. Jordi Ah! Què vem dir?

20. Teacher Què vau pensar.

21. Raquel Què podrien fer?

22. Teacher Yes, or what kind of things are there in el Montseny? [to do], or to see or..

23. Jordi $[\mathrm{Ah}]$

24. Mike Quines coses hi ha per fer en el Montseny?

25. Teacher Yes.

26. Jordi Bueno, no se...XXX

27. Teacher Come on, tell me! Si ho vau fer XXX

28. Raquel Tens els fulls? 
29. Teacher Yes, els tinc.

30. Xavi Pues diga-ho!

31. Mike Està gravant la càmera aquesta?

32. Teacher Can you answer my question? Nobody remembers?

33. Students No! XXX

Nevertheless, students did not seem to consider that explaining similar information to Kate constituted a repetition of previously reviewed information; the fact that they knew that Kate did not have access to the information in the worksheets they had previously prepared enhanced the perception of having a real purpose for giving her information, even if it meant repeating what they had already said on a previous occasion. The use of a digital resource allowed distancing of the students from the curricular topics and introduced a way to practice the target language with a realistic need for communication. As it can be seen in this extract, Kate asked a similar question to the one that the teacher had previously asked but the students answered completely differently.

Extract 5. Kate asks about answers in worksheets

323. Kate (..) All right! I have something some other questions. What about families that like nature?

324. Mike We've got lovely mountains in Catalonia.

325. Kate Ok! Lovely mountains. Any one in particular?

326. Mike Montseny, Montseny.

327. Kate Montseny, ok.

328. Dani Turó de l'Home.

329. Jordi What can they do in Montseny?

330. Mike Walk around.

331. Xavi Turo de l'Home!

332. Kate But I'm sorry.

333. Mike What? Could you repeat the question, please?

334. Kate Yes, what can they do in Montseny, they can walk and what else?

335. Mike They could go cycling as well.

336. Kate Oh very nice. Walking and cycling... sounds very nice! Ok! 
337. Xavi (Asking to Teacher) Escalar? Es que no m'en recordo...

338. Teacher Rock climbing.

339. Xavi (To Kate) Rock climbing.

340. Kate OK climbing. Wonderful! That sounds like a wonderful place to visit.

\section{Conclusions}

This short-term study adds to the existing literature which argues that using digital tools in pedagogically informed ways can be beneficial for language learning practices, and suggests that teachers should start reflecting on its importance and applying it at least in small amounts in their daily teaching routines. As the data analysis has indicated, the presence of the Internet-based communication tool created the potential for purposeful, powerful use of online communication in the language class because the messages were intended to establish contact between students and the interlocutor on the other side of their screen (Kern, 1995). As stated by Kern (1995: 470), "CMC is not the solution for a perfect language acquisition, nor a substitute for normal classroom practices, but it offers restructured classroom dynamics and a new context for social use of language."

The findings suggest that one of the main benefits that ICT brings into the language classroom is the ability to create a real necessity for students to speak in the target language and to try to have a conversation because digital tools can bring them into contact with circumstances from the outside world (creating authenticity). This means that the dynamics of the classroom are completely changed, as well as the type of interaction that takes place. Moreover, this authenticity of communicative situation in the classroom enhanced their interest; students found a real goal to practice the target language.

Of course, due to the narrow and descriptive nature of this study, generalizations should be made cautiously. Nevertheless, it has been shown that the use of videoconferencing to develop communication can be a beneficial approach that provides language learning opportunities as long as the use of these tools is implemented through appropriate and engaging tasks. The results of this research do not fall on the use of the digital tool itself but how this artifact has been put into action in order to offer authentic contexts and a real need of 
communication, to engage student's attention and motivation on the task and enhance interaction and thus language mediation processes among them.

Last but not least, it is important to emphasize the need for more research in this field, specifically in the context of Primary Education in Catalonia, where CMC integration is not commonplace. Research to date, including the present investigation has demonstrated that ICT, integrated in an appropriate communication-based pedagogy brings important benefits to language learning, but little research has been carried out on the quantity of use of target language, its quality compared to other learning situations; or how $\mathrm{CMC}$ tools (other than Skype) can enhance language interaction in primary education. Hopefully further research will help orient language teachers in the use of digital tools for creating positive processes that let students co-construct new language knowledge, and provide additional input on how these processes can lead to more positive results.

\section{References}

Blake, R. (2000). Computer mediated communication: A window on L2 Spanish. Language Learning \& Technology, 120-136.

Breen, M., \& Candlin, C. (1980). The essentials of a communicative curriculum in language teaching. Applied Linguistics, 1: 89-102.

Brooks, L., \& Swain, M. (2001). Collaborative writing and sources of feedback: How they support second language learning. OISE/UT manuscript.

Bruner, J. (1985). Vygotsky: A historical and conceptual perspective. A J. V. (Ed.) Culture, communication and cognition: Vygotskyan, (pp. 21-34). New York: Cambridge University Press.

Charmaz, K. (1995). Grounded theory. In J. Smith, R. Harré, \& L. Langenhove, Rethinking methods in psychology (pp. 27-65). London: Sage Publications.

Charmaz, K. (2006). Constructing grounded theory. A practical guide through qualitative analysis. London: SAGE Publications.

Cohen, L., \& Manion, L. (1980). Research methods in education. London: Croom Helm.

Cummins, J., \& Sayers, D. (1995). Brave new schools: Challenging cultural. New York: St. Martin's Press.

Dick, B., \& Swepson, P. (2012). Action research resources. Retrieved from http://www.aral.com.au/

Dooly, M. (2008). Telecollaborative Language Learning. Bern: Peter Lang.

Dooly, M. (2010). Teacher 2.0. In: Telecollaboration 2.0. Language, literacies and intercultural learning in the 21st century. In S. Guth \& F. Helm, (Eds.) (pp. 277-303). Bern: Peter Lang.

Dooly, M., \& Sadler, R. (2013). Filling in the gaps: Linking theory and practice through telecollaboration in teacher education. ReCALL, 4-29.

Gass, S., \& Varonis, E. (1994). Conversation interactions and the development of L2 grammar. Studies in Second Language Acquisition, 16: 183-302. 
Glaser, B. G., \& Strauss, A. L. (1967). The discovery of grounded theory: strategies for qualitative research. Chicago: Aldine Publishing Company.

Kern, R. (1995). Restructuring classroom interaction with networked computers: Effects on quantity and characteristics of language production. The Modern Language Journal, 79(4), 457-476.

Kern, R. (2000). Literacy and language teaching. Oxford: Oxford Universty Press.

Kern, R. G., \& Warschauer, M. (2000). Network-based language teaching: Concepts and practice. (Vol. 4). New York: Cambridge University Press.

Kern, R., Ware, P., \& Warschauer, M. (2004). Crossing frontiers: New directions in online pedagogy. Annual Review of Applied Linguistics, 243-260.

Kowal, M., \& Swain, M. (1997). From semantic to syntactic processing: How can we promote it in the immersion classroom? In: M. Johnson \& M. Swain (Eds.), Immersion education: International Perspectives (pp. 284-309). New York: Cambridge University Press.

Kress, G. (2003). Literacy in the new media age. London: Routledge.

Kress, G., \& van Leeuwen,T. (2001). Multimodal discourse: The modes and media of contemporary communication. London: Arnold.

Lam, W. (2000). L2 literacy and the design of the self: A case study of a teenager writing on the Internet. TESOL Quarterly, 457-482.

Lantolf, J. P., \& Thorne S. L. (2006). Sociocultural theory and the genesis of second language development. Oxford: Oxford University Press.

Mehan, H. (1985). The structure of classroom discourse. In: T. A. Dijk (Ed.), Handbook of discourse analysis (pp. 120-131). London: Academic Press.

O'Brien, R. (2001). An overview of the methodological approach of action research. Retrieved from Theory and Practice of Action Research: http://www.web.ca/ robrien/papers/arfinal.html

O'Dowd, R. (2006). Telecollaboration and the development of intercultural communicative competence. Berlin: Langenscheidt.

Pelletieri, J. (2000). Negotiation in cyberspace: The role of chatting in the development of grammatical competence. In M. Kern, Network-based language teaching: Concepts and practice (pp. 59-86). New York: Cambridge University Press.

Pica, T. (1994). Research on negotiation: What does it reveal about. Language, 3(44), 493527.

Ratner, C. (2002). Cultural psychology: Theory and method. New York: Kluwer/Plenum.

Richards, J. (2006). What is communicative language teaching? In: J. Richards (Ed.), Communicative language teaching today (pp. 2-5). New York: Cambridge University Press.

Riel, M. (2011). Understanding action research. Retrieved from Center for Collaborative Retrieved 21 February 2013 from Action Research: http://cadres.pepperdine.edu/ccar/define.html.

Rivers, W. (1993). Interaction as the key to teaching language for communication. In W. Rivers (Ed.), Interactive language teaching (6th ed., pp. 3-16). Cambridge: Cambridge University Press.

Savignon, S. (1983). Communicative competence: Theory and classroom practice. Reading, MA: Addison-Wesley.

Smith, B. (2003). Computer-mediated negotiated interaction: An expanded model. Modern Language Journal, 38-57. 
St. John, E., \& Cash, D. (1995). Language learning via e-mail: Demonstrable success with German. In M. Warschauer, Virtual connections: Online activities and projects for networking language learners (pp. 191-197). Honolulu: University of Hawai'i, Second Language Teaching and Curriculum Center.

Swain, M., Brooks, L., \& Tocalli-Beller, A. (2002). Peer-peer dialogue as means of second language learning. Annual Review of Applied Linguistics, 9(22), 171-185.

Thorne, S. (2003). Artifacts and cultures-of-use in intercultural communication. Language Learning \& Technology, 38-67.

Thorne, S. (2008). Mediating technologies and second language learning. In: J. Coiro, M. Knobel, C. Lankshear, \& D. Leu, Handbook of Research on New Literacies (pp. 417449). Mahwah, NJ: Lawrence Erlbaum.

Thorne, S. L., Black, R. W., \& Sykes, J. M. (2009). Second language use, socialization, and learning in internet interest communities and online gaming. The Modern Language Journal, 93: 802-821.

Tudge, J. (1990). Vygotsky, the zone of proximal development, and peer collaboration: Implications for classroom practice. In L. C. Moll (Ed.), Vygotsky and education: Instructional implications and applications of sociohistorical psychology (pp. 155172). Cambridge: Cambridge University Press.

Vygotsky, L. S. (1978). Interaction between learning and development. Cambridge, MA: Harvard University Press.

Vygotsky, L. S. (1981). The genesis of higher mental functions. In J. V. Wertsch (Ed.), The concept of activity in Soviet psychology (pp. 144-188). Armonk, NY: M. E. Sharpe.

Warschauer, M. (1997). Computer-mediated collaborative learning: Theory and practice. The Modern Language Journal, 470-481.

Warschauer, M. (1999). Electronic literacies: Language, culture, and power in online education. Mahwah, NJ: Erlbaum.

Warschauer, M. (2000). Online learning in second language classrooms: An ethnographic study. In: M. W. Kern (Ed.), Network-based language teaching: Concepts and practice. (Vol. 4). (pp. 41-58). Cambridge: Cambridge University Press.

Wells, G. (1999). Dialogic inquiry: Toward a sociocultural practice and theory of education. Cambridge: Cambridge University Press.

\footnotetext{
Author's Reference:

Aida Cuestas Verjano holds a Master's degree in Language and Literature Teaching from the Universitat Autònoma de Barcelona (Spain). She currently works as an English teacher in a primary school in Catalonia. Her research interests lie in the use of new technologies in education, especially as applied to the area of Teaching English as a Foreign Language (TEFL).

Email: aidacuestas@gmail.com
}

To cite this article:

Cuestas Verjano, A. (2013). Using skype in a primary class: A case study. Bellaterra Journal of Teaching \& Learning Language \& Literature, 6(2), 49-68. 